\title{
La vuelta a Marx: el problema de la fundamentación del materialismo encarnado
}

The return to Marx: the problem of the foundation of embodied materialism

Karol Badilla-Fallas

Universidad de Costa Rica - Costa Rica

San José, Costa Rica

karol.badilla@ucr.ac.cr

\section{RESUMEN}

En este artículo se analizan los fundamentos del materialismo encarnado presente en Ariel Salleh, como una respuesta al debate ecofeminista sobre el papel de las mujeres en su relación con la naturaleza. Se examina la diferencia de este materialismo con el materialismo ecológico de Marx, y los beneficios de una postura que busca la reconciliación del materialismo encarnado con los fundamentos marxianos, a fin de recuperar la riqueza conceptual que significa su incorporación dentro de los debates del ecofeminismo marxista.

Palabras clave: crisis ambiental; ecofeminismo; marxismo; materialismo encarnado; trabajo femenino.

\section{ABSTRACT}

This article analyzes the foundations of the embodied materialism present in Ariel Salleh, as a response to the ecofeminist debate on the role of women in their relationship with nature. The difference between this materialism and Marx's ecological materialism is examined, and the benefits of a position that seeks the reconciliation of embodied materialism with Marxian foundations, in order to recover the conceptual richness that its incorporation into the debates of Marxist ecofeminism means.

Keywords: environmental crisis; ecofeminism; Marxism; embodied materialism; female work. 


\section{Introducción}

\section{El ecofeminismo de Salleh}

Desde los años 70's, la corriente ecofeminista se creó como teoría para intervenir y analizar la forma en la que la destrucción de la naturaleza se relaciona con las mujeres. La crisis ambiental se presenta como un asunto que le compete por completo a los movimientos feministas, ya que representa y ayuda a comprender toda una escala de factores que influyen en la dominación por género (Warren, 2000, p. 1).

El ecofeminismo que se desprende de la corriente feminista-marxista tiene como una de sus metas, la atención especial a la relación entre el sistema de producción capitalista, el desequilibrio ecológico que conlleva y las consecuencias para las mujeres más vulnerables. Un ecofeminismo cercano al pensamiento de Karl Marx (1818-1883) es defendido en la obra de Ariel Salleh (2017) Ecofeminism as Politics; Nature, Marx and the Postmodern, cuyo debate ha tomado importancia desde que se editó el libro por segunda vez después de 20 años. En dicha obra se presentan tres conceptos fundamentales que pueden ayudar al análisis: "trabajo meta-industrial”, "materialismo encarnado" y "dialéctica ecofeminista de las relaciones internas". En este artículo, se prestará atención al materialismo encarnado y de forma secundaria al trabajo meta-industrial.

El trabajo meta-industrial, como una actividad separada de la producción capitalista, es, según Salleh, condición social necesaria en una política ecológica-feminista (2017, p. 41). Este trabajo meta-industrial, depende en gran medida del proceso histórico que viven las mujeres desde sus infancias, un proceso que las convierte en productoras de materia para la regeneración del planeta por medio de sus actividades. Esto es en resumidas cuentas la idea principal detrás del materialismo encarnado. Salleh afirma que el capitalismo se sostiene en gran medida del trabajo meta-industrial y el materialismo encarnado. Un trabajo que producen las mujeres directamente en su relación con la naturaleza. Asumir este materialismo encarnado, le parece a Salleh una base para posicionar a las mujeres como sujetas sociales capaces de elaborar una ética ambiental cuya labor y sensibilidad política, no está implicada en la industrialización y sus parcelas de tiempo administrado (2017, p. 19). En esto se acerca más al feminismo marxista; el "desarrollo sostenible” le parece un oxímoron, ya que la crisis sólo puede ser remediada fuera del capitalismo. Sin embargo, no aborda de manera explícita cómo el materialismo encarnado también se aprende dentro del sistema capitalista y funciona a su favor directamente. Es decir, si es un hecho la apropiación del capitalismo de estas actividades, ¿cómo es que se encuentran, a su vez, separadas de la producción capitalista?

Este problema resulta de las objeciones que tiene la australiana con respecto a la teoría de Marx. Por un lado, acepta el debate entre la humanidad y la naturaleza que postula, sin aceptar la supremacía del ser humano por sobre ella. Una de sus críticas más importantes es el antropocentrismo que ella detecta en la forma en la que se trata la naturaleza a lo largo de sus escritos (2017, p. 100). Por otro lado, tiene críticas a la teoría del valor ya que, para ella, aún conserva las características antropocéntricas y patriarcales de la lógica de dominación. Además, parece que en Marx, la objetivación de la subjetividad femenina organizada por el hombre para el servicio de sus necesidades diarias, pasa como un simple hecho social de corte natural. Es 
una "condición económica de producción” justo como la naturaleza lo es (Salleh, 2017 p. 104). El trabajo femenino estaría escondido detrás del abaratamiento del salario para los obreros.

La lógica a la que se refiere Salleh, contiene diferentes ideas dominantes, y una de ellas se deriva de la separación entre el cuerpo y la mente llevada a cabo en el siglo XVII. Por esto dice que su materialismo es encarnado. La necesidad de pensar otra lógica corporal, es una de las grandes demandas de este pensamiento encarnado. Es importante, como primer punto, reivindicar el materialismo que no es mecanicista, que no trata al cuerpo como una máquina (Wolfe, 2012, p. 129). Aquí sería todo lo contrario, el pensamiento que está separado del cuerpo es lo que hace un cuerpo títere, marioneta. Reclamar que el pensamiento y las ideas se producen en un cuerpo que siente, con emociones que comparten el mismo espacio, es una ruptura con la lógica de dominación.

Salleh no recurre a Marx ni al epicureísmo para explicar este tipo de materialismo, no cuando dentro de su propia crítica a la lógica de dominación está incluido el filósofo alemán. Así, la explicación que se da es una crítica a la hegemonía patriarcal y opresiva que se expresa en la lógica de las ciencias occidentales. Para esto recurre a la sociología del conocimiento, mediante el rastreo de ideas que se vuelven fundamentales para organizar las relaciones sociales (2017, p. 68). La primera de las lógicas es el principio de no contradicción: A y no A, también se refiere a ella como la cultura del 1/o. En realidad, Salleh postula que la cultura de 1/o solo revela como el ego capitalista-patriarcal experimenta el vacío (o) y debe constantemente afirmarse a sí mismo consumiendo la energía de otros: mujeres, niños, nativos (2017, p. 76). Esta tradición de pensamiento dominante se puede observar desde Aristóteles, pasando por los patriarcas de la Iglesia católica, Bacon, Locke, Hegel y llega a Marx (2017, p. 69).

Foster (2000) tiene una crítica contra este tipo argumentación dentro de los estudios ecoambientales. Comprende que existe un problema en la fundamentación del materialismo, no solamente dentro del materialismo de Marx, sino de la herencia que se tiene del materialismo desde la antigüedad (200, p. 14). La misma idea de que el materialismo moderno comenzó con la ciencia occidental se trata aquí como errónea. Para los análisis ecológicos, Foster considera necesario examinar las ideas sobre la naturaleza que se desarrollaron entre XVII y XIX. Precisamente en la época de Darwin (a quien asocia con el materialismo), y Marx. Esto anterior le parece necesario, basado en sus propios estudios de la teoría ecosocialista. Ya que la crítica a la ciencia occidental alcanza al pensamiento marxiano, la teoría ecosocialista prefiere la exclusión de su materialismo para la fundamentación de una crítica ecológica. Esto en un grave error, según su criterio, ya que a su parecer "el materialismo hizo posible los modos de pensar ecológicos" (p. 17).

Foster califica esta fundamentación del materialismo como esencialista o reduccionista:

Sin embargo, al centrarse en el conflicto entre el mecanicismo y el vitalismo o idealismo ( $y$ al perderse de vista la cuestión más fundamental del materialismo) se cae en una concepción dualista incapaz de reconocer que estas categorías están dialécticamente relacionadas en unilateralidad, y deben de trascenderse conjuntamente, puesto que representan la alienación de la sociedad capitalista. (2000, p. 32) 
Esto crea un enfoque de los estudios en un "extraño contexto idealista", donde "desaparecen los temas histórico-materiales reales". Sin embargo, a Foster le parece que Salleh con su materialismo encarnado supone una excepción aún dentro de las teorías verdes que critica (p. 383). Al menos evita caer en un excesivo enfoque en el impacto económico, otro de los problemas que detecta el pensador. Es decir, el materialismo encarnado puede potencialmente ayudar a explicar las relaciones complejas que necesita explicar la teoría ecológica.

Pamela Odih (2014) también considera que la exclusión del materialismo marxiano dentro de este otro materialismo es problemática. En el prólogo de su obra Watersheds in Marxist Ecofeminism se refiere explícitamente a Salleh y el problema de los dualismos de dominación que ella identifica en la obra de Marx. Uno de los puntos principales es examinar la construcción de la jerarquía entre los hombres y la naturaleza que se establece, y la crítica a los fundamentos del materialismo histórico (p. LI). Su intención para analizar esto, es poder crear un diálogo conceptual entre el marxismo clásico y el ecofeminismo contemporáneo. Odih comienza su análisis desde el materialismo que dio origen a la propia concepción de Marx: el atomismo de Epicuro y Lucrecio. Para ello se refiere a la tesis doctoral de 1841 y su crítica al determinismo atómico de Demócrito (p. Iviii). El clinamen de Epicuro, la forma en la que un átomo sale de la caída en línea recta, irrumpió la ciega necesidad que tenía el atomismo democríteo. Para esta pensadora, en esta tesis de juventud, se puede observar la relación que está construyendo Marx con la naturaleza. Odih sostiene que esta relación la mantendrá a lo largo de su vida.

Para Odih la discusión sobre la separación de este materialismo y sus diferentes "tiempos" es crucial. La separación del tiempo de la producción y la reproducción le parecen un "dualismo" de estos mismos que el ecofeminismo intenta superar. La autora asegura que estos dualismo, no están contribuyendo al impacto político de los análisis ecofeministas, en realidad disminuyen su efectividad (p. LXXIV). Así, procede a referirse a esta separación como un dualismo esencialista: "While emphatically agreeing with the principle of this argument, it is necessary to avoid essentialism and dualistic categories in the formulation of the concept of reproduction time" (p. LXXV). Para ella, estas formulaciones separadas, están lejos del clinamen epicúreo. Estos esencialismos, por ejemplo, le darían un lugar al trabajo femenino que lejos de empoderarlo, lo convierte en una suerte fatal que tiene todas las mujeres desde el nacimiento.

Nuevamente, Foster y Burkett (2016), se refieren a las críticas que se han hecho a la concepción "antropocéntrica" de la naturaleza en Marx (otra de las críticas de Salleh). Estos enfoques "se rehúsan a encargarse de todos los complejos temas que tal crítica contemplaría". Entre ellos, el hecho de que la visión marxiana sobre la interacción entre los seres humanos y la naturaleza es materialista y dialéctica. “(...) so, that the crucial question becomes the nature of the interaction that takes place (...)” (p. 64). Es decir, la fractura metabólica que plantea el análisis del capitalismo en Marx se deja de lado. Esto mismo se pone en cuestión al pensar en las condiciones socioeconómicas de las mujeres que participan en el materialismo encarnado de Salleh.

Como se ha venido comentando anteriormente, parte de la riqueza conceptual y la aproximación al conocimiento que planteó el pensador alemán, es opacada con la exclusión definitiva de su materialismo. Los autores retoman la crítica que hace Salleh (2017) sobre el antropocentrismo en Marx. En especial la idea de la naturaleza como "cuerpo inorgánico del hombre": "La cuestión de la naturaleza como cuerpo inorgánico del hombre no debe descartarse como un mero punto 
de vista instrumentalista y antropocéntrico. Hacerlo es sucumbir a un enfoque fundacionalista estático de la ética ambiental, divorciado de la historia y la evolución" (Foster y Burkett, 2016, p. 64). Según estos autores, las críticas que tiene Salleh contra Marx, parten de una mirada más reducida del alcance que tiene su análisis: "no están informadas por una examinación cercana y comprensiva de los textos de Marx" (Foster y Burkett, 2016, p. 84). El libro de Salleh Ecofeminism as Politics; Nature, Marx and the Postmodern si demuestra una lectura cercana y atenta de los textos de Marx, por lo que esta acusación no se sigue. La otra, sobre si la lectura de Salleh es comprensiva, podría ponerse en discusión. Nuevamente se le acusa de reducir los términos a un dualismo, uno que no permite ver la "interdependencia ecológica".

El problema que se presenta a continuación es la fundamentación del materialismo encarnado en el vitalismo, el psicoanálisis y la exclusión del materialismo marxiano. Además de la propia lectura de Marx que realiza la pensadora. La lógica que nos presenta Salleh excluye a las mujeres de una identidad asignándoles 0 , y después, defiende que son los hombres quienes en realidad experimentan este vacío y han volteado el pensamiento. Los hombres experimentarían una especie de vacío con respecto al materialismo encarnado por nunca poder experimentarlo. A pesar de que Salleh indica que no sólo a través de la reproducción social (específicamente el parto) las mujeres experimentan un materialismo encarnado, no da otros ejemplos prácticos que puedan ayudar a entender cómo impacta de manera socio-económica este materialismo y ciertamente no se refiere al trabajo femenino que no se percibe como meta-trabajo. Es decir, su materialismo no es práctico.

Querer establecer una distancia con el materialismo de Marx, elimina la crítica económicopolítica del horizonte de este materialismo encarnado. Salleh inclusive llega a hipotetizar que el ecofeminismo podría trabajar bien con las feministas liberales si estas ampliaran su visión:

Las ecofeministas y las feministas liberales podrían trabajar juntas, si las femócratas estuvieran de acuerdo en ampliar sus horizontes políticos virtuales más allá de maximizar las opciones en las selvas del hormigón, las dioxinas y el acero. Muchas feministas liberales están bien conectadas y son capaces de encontrar espacios para que las activistas indígenas, del Tercer Mundo y ecofeministas sean escuchadas en la corriente política dominante (2017, p. 141).

¿Tiene que sacrificar el feminismo su anticapitalismo para ser escuchado? Este no tiene porqué ser el caso, y el feminismo liberal no va a ampliar su visión por sus intereses de clase.

El trabajo femenino no podría ser tal si no fuese por el conocimiento material que ellas aprenden, comprenden y sienten. El capitalismo como sistema de producción necesita trabajo barato y el materialismo encarnado de las mujeres puede funcionar a su conveniencia, dentro de su lógica. La teoría ecofeminista-marxista (y cualquiera que se pretenda anticapitalista) debe escribir exhaustivamente sobre el gran parte del porcentaje de mujeres que trabajan para el capital. El materialismo encarnado ayuda a fundamentar un punto dentro de la socialización sumamente profundo, sin embargo, no alcanza para explicar satisfactoriamente este proceso a menos que se haga una crítica radical utilizando su propia riqueza conceptual. 


\section{Metodología}

Para esta investigación se ha preparado una crítica conceptual que se enfoca en la discusión sobre el materialismo encarnado de Salleh dentro de la teoría ecofeminista y sus alcances. Esto implica primero, un análisis conceptual de los dualismos occidentales sobre los cuáles invita a reflexionar Salleh. Algunos de estos conceptos se han desarrollado dentro de la teoría ecofeminista como una de las bases de su crítica. Uno de ellos es el de mente/cuerpo al que pertenece el materialismo de Salleh, otro es civilización/primitivo, producción/reproducción, sociedad/ naturaleza y hombre/mujer (Tardón, 2011, p. 535). La teoría feminista marxista ha reflexionado en estos dualismo también, principalmente el de producción/reproducción (Federici, 2018, p. 13). Dentro del ecofeminismo marxista es necesaria una examinación que tenga como punto de partida la relación con la naturaleza.

De igual manera, el trabajo femenino que se presenta en la investigación ha sufrido un proceso de abstracción al igual que la mayoría de conceptos. Para esto se toman los conceptos y se comparan, aislando aquellos que se consideran esenciales (Foladori, 1990, p. 20). Ordenar y descubrir las relaciones conceptuales detrás de los conceptos abstraídos, permite mirar hacia lo concreto nuevamente, esta vez con una mirada más clara (p. 21).

\section{Desarrollo}

\subsection{El materialismo encarnado de Salleh}

En este apartado se examinará de forma más detallada el materialismo encarnado que es protagonista en la investigación. Varios de los puntos que componen este concepto ya han sido adelantos en la introducción: se sabe que el materialismo encarnado está relacionado directamente con un proceso histórico que viven las mujeres donde se les enseña a ser sostén material del planeta. La base de este materialismo es el trabajo meta-industrial y está formado de las tareas ya conocidas que componen el trabajo femenino: la reproducción directa de la especie, el cuido de niños, adultos u otras personas que lo requieran, la preparación de alimentos, la limpieza, la agricultura y el cuido de animales.

¿De dónde surge la necesidad por posicionar un materialismo con estas características? En el artículo Moving to an Embodied Materialism (2006) la sociológa australiana se refiere a la iniciativa que tuvieron en la Revista Capitalism Nature Socialism por encontrar un lenguaje político en común para los ecosocialistas y las ecofeministas (p. 9). Según su criterio, las ecofeministas han reclamado a los movimientos socialistas y ecosocialistas, la aceptación de la división por género como "la más profunda de las opresiones sociales" que viven las mujeres en las sociedades. Este reconocimiento sería un "primer momento político” que ambos movimientos podrían compartir. Un segundo movimiento es la práctica de habilidades en las organizaciones de resistencia para que no sean consumidas por la lógica de dominación que implica negar lo primero. El tercer momento político, que es el más pertinente para esta investigación, es la capacidad de dialogar y re conceptualizar allí donde es necesario gracias a este esfuerzo (p. 10).

El materialismo encarnado cumple parte del tercer momento político. Una de sus intenciones es que los temas que involucran la opresión por género y el medio ambiente, no sean catalogados como temas "de mujeres" (2006, p. 11). Vista como una materia separada de los movimientos 
ecosocialistas, las perspectivas de las ecofeministas se han tachado de esencialistas, excluyentes o deterministas, cuando su realidad abarca múltiples aspectos donde interactúan las sociedades en su conjunto.

La división sobresale en su análisis para explicar la diferencia en la configuración del poder que ejerce el patriarcado y el capitalismo, pero no para separar a los movimientos:

Para los socialistas, la clase capitalista, sus compinches del gobierno y los parásitos del estilo de vida son el amo, y su casa es la esfera pública global. Para las ecofeministas, esto también es cierto, pero hay otro amo encarnado en las relaciones de poder privadas que rigen la vida cotidiana de las mujeres en el hogar, en el trabajo y en la academia (Moving to an Embodied Materialism, 2006, p. 11).

Así, una de las características que podemos añadir a este materialismo encarnado es que se aprende en la parte privada de la sociedad y luego se manifiesta "públicamente en el trabajo y la academia". Las relaciones de poder que se encarnan en las mujeres, se ven aquí como independientes de su relación económica. Por esto se usa el doble patriarcado-capitalismo, ya que antes de que existiera el capitalismo, la opresión hacia las mujeres ya las había convertido en sostén material del planeta. El capitalismo como modo de producción es la "última" de las formas económicas en las que dicha opresión patriarcal se hace manifiesta. Es decir, las mujeres sufren doble opresión: en la esfera pública por el capitalismo y en la privada por el patriarcado.

Salleh (2009) aclara en otro artículo, que esta relación que menciona no pretende excluir a los hombres de la dominación capitalista, e inclusive que algunas mujeres en el norte del globo se han beneficiado del crecimiento destructivo (p. 21). Lo que sucede es que sí existe una diferencia en la configuración de la vida entre hombres y mujeres: "Porque el hecho es que en al menos cuatro formas la relación de las mujeres con la "naturaleza” y, por lo tanto, con el "capital” y el "trabajo", se construye de manera diferente a la de los hombres" (2009, p. 22). Se puede observar la influencia del materialismo feminista en esta observación. La primera de estas diferencias se refleja en el papel que tienen hombres y mujeres en el momento de la reproducción de la especie. La conciencia de las mujeres es plena durante la gestación y el parto, mientras los hombres juegan papeles secundarios. La segunda de las diferencias tiene que ver con el trabajo asignado a las mujeres históricamente, y que, a su mismo tiempo, sirve como puente entre los hombres y la naturaleza. La tercera está reflejada en la capacidad curativa de las mujeres y su mantenimiento de la vida por medio de sus aportes a la preservación de la misma en sus roles de agricultoras, herbalistas, curanderas, etc.

La última de estas diferencias tiene que ver con la forma en la que las mujeres han sido representadas en las expresiones culturales con lo "femenino" y la "naturaleza" también femenina. Salleh afirma que todo esto en conjunto representa una aproximación al conocimiento sobre la vida que es diferente: “A través de esta constelación de trabajos, las mujeres están orgánicamente y discursivamente implicadas en actividades que afirman la vida y desarrollan conocimientos específicos de género basados en esta base material" (2009, p. 22). La primera de estas relaciones envuelve el cuerpo de las mujeres y es una de las diferencias por las que el materialismo aparece como "encarnado". Salleh se refiere a esto como el "interjuego del parto y la lactancia". Ambas 
experiencias, el parto y la lactancia, le permiten afirmar que la orientación epistemológica de las mujeres se transforma en un materialismo encarnado (2017, p. 71).

El materialismo encarnado de Salleh vuelve a esta concepción del cuerpo en lo que llama reproductive consciousness, la concientización plena de la reproducción. En ese sentido, un parto, por ejemplo, representa una experiencia que labra el significado y el valor de la vida en la carne misma (p. 70). Sin embargo, la paternidad vuelve a reinstalar el 1/o con la apropiación de los seres humanos que nacen de la reproducción. Además, para los hombres la reproducción se ve desde afuera, no se siente. Salleh (2017) se apoya en el psicoanálisis para determinar esto anterior:

Si bien este hábito de pensamiento no es necesariamente universal, es sintomático de una sociedad amante del falo que privilegia la vista sobre todos los demás sentidos. Psicoanalíticamente, la proposición dice: dado que solo el Hombre tiene 1, él es uno. Cuando miras a Mujer, por el contrario, ves solo o, un agujero, cero. Por tanto, se la define negativamente como una carencia. La mujer es “inferior”, “diferente”, Otro. (p. 68)

Los hombres blancos occidentales, se han fundamentado en la identidad A según esta lógica. Las mujeres y todos los demás grupos que no encajan con ellos se transforman en meras no identidades, cuya única oportunidad de identidad se relaciona con Salleh afirma que no es un universalismo, pero el resto de las explicaciones que se dan sobre esto generalizan en la forma en la que se han construido las relaciones entre hombres y mujeres.

Algo muy similar se plantean Patel y Moore (2018) cuando comentan como el abaratamiento de la naturaleza durante la colonia también estuvo influido por esta lógica excluyente. Inclusive fue utilizada por el Papa Nicolás V para autorizar la esclavitud de los aborígenes en 1452 (p. 101) La civilización europea debía convertirse en "los amos y señores de la naturaleza” y los aborígenes eran parte de la “naturaleza” y lo salvaje (p.63). Salleh (2017) comenta como desde las metrópolis se "exporta” esta lógica hasta las periferias del capitalismo (p. 69).

Como ya se ha adelantado previamente, esta lógica de exclusión se encuentra en el análisis marxiano. Salleh toma un par de ejemplos de Marx llamando a la tierra "dama” y al capital "señor", pero esto es mucho más profundo que unas simples palabras. La formulación del dualismo hombre/naturaleza sigue en el pensador alemán, y la necesidad de tomar el control de la naturaleza también. Salleh explica esto con el ejemplo usado en El Capital de las máquinas como naturaleza "cayéndose a pedazos": quedarse en la naturaleza primera es dramatizar el predicamento humano, de que aquello que el capital puso en marcha, sale del control nuestro, es naturaleza que se "descarrió" y permanece por fuera del control consciente, (p. 103). Así, la conciencia que se tome, debería volver a tomar el control sobre esta naturaleza. Nuestra socióloga se pregunta si esto fue un recurso retórico que toma Marx para enardecer el ánimo de los obreros, más allá de una verdadera intención por aceptar la lógica binaria de dominación.

Su crítica a la teoría del valor, que está influenciada directamente por el feminismo materialista, se manifiesta. La construcción de la historia de la humanidad depende del trabajo productivo como un momento en el que la subjetividad humana se objetivó. ¿Por qué no de la reproducción? Se pregunta. La reproducción como condición material que ha creado a la humanidad, es empíricamente más probable que se utilice como base, (p. 102). Una vez más, la idea de la 
producción y el lugar que ocupan los hombres en ella, le parece a Salleh "sintomática" de la destrucción que lleva inherente (p. 73).

Para Salleh la prueba está en la desesperada cruzada que lleva a cabo la ciencia para apoderarse de las habilidades reproductivas de las mujeres. Esto también tiene relación con el reclamo de Mies y Shiva (1998). El desarrollo de estas ultra tecnologías para la concepción, la imitación del útero materno y el creciente mercado que subroga el cuerpo de las mujeres para tener hijos no es una necesidad de las mujeres, mucho menos de las más pobres. El desarrollo de esas tecnologías es una necesidad del capital (p. 28). La fecundidad se nota como una enfermedad entre las mujeres pobres y es conocida la técnica que se aplica para la esterilización de estos grupos, pero no para otros intereses (p. 48).

Más allá de este punto, la explicación que brinda Salleh (2017) sobre la reproducción y su relación con la lógica de dominación se vuelve primordialmente psicoanalítica. Esto lo hace primero mediante el análisis estructural psicoanalítico lacaniano. Para esto recurre a la pensadora Julia Kristeva y su teoría de la fobia que se desarrolla al separarse de la madre. El miedo masculino a las secreciones corporales de las mujeres viene del otro lado del ego narcisista: lo desagradable, lo corpóreo no es racional ni pertenece al ámbito de los hombres (p. 74). La figura de agradar al padre y el complejo de Edipo también entra en juego para establecer la diferencia de la conciencia reproductiva en hombres y mujeres. El vacío que experimentan los hombres se explica así:

\footnotetext{
La competencia agresiva en los deportes, la posesión de la propiedad, el control administrativo de Otros, la manipulación tecnológica de la naturaleza son instrumentos de seguridad. Por tanto, el complejo Hombre / Mujer = Naturaleza puede leerse como una compensación ideada colectivamente por la pérdida de la integridad del yo. La preocupación por la potencia personal en todas sus manifestaciones sociales, la remodelación del entorno según la voluntad masculina, estas cosas mitigan el vacío del yo sin fundamento (p. 76).
}

¿Quiere decir esto que el patriarcado es solo una forma de reafirmarse? La pérdida de la identidad del yo no alcanza para explicar la propiedad privada de los hombres y cómo la acaparan. Esto no funciona como una excusa convincente y de esto es consciente la propia pensadora. Sin embargo, la fundamentación del materialismo encarnado en este tipo de diferencias termina por hacerla afirma cosas tales como: la quietud del feminismo de mediana clase occidental tiene que ver con el "narcisismo" implicado en su interior. Es su cultura narcisista (2017, p. 132). Visto únicamente desde el interior, el individualismo que esto expresa se asemeja a las afirmaciones del feminismo liberal sobre la situación de las mujeres.

\subsection{La vuelta a Marx}

Con todo lo mencionado anteriormente, parece comprensible abandonar el materialismo encarnado de Salleh para abordar el problema de la relación de las mujeres desde una perspectiva que resulte menos problemática. Sin embargo, como ya se ha adelantado, parte de la concepción de este materialismo en específico es muy interesante y resulta útil para comprender las relaciones dialécticas que se conforman entre las mujeres y la naturaleza. Especialmente dentro de las sociedades capitalistas. ¿Cómo sacar al materialismo encarnado de su esencialismo? ¿Cómo 
dotarlo de crítica anti-capitalista para que ayude a re conceptualizar los estudios ecofeministas marxistas? Lo que se debe es buscar una postura que permita reconciliar parte de los fundamentos de este materialismo con la teoría marxiana.

Lo primero que resulta importante, es la fundamentación de este materialismo en el materialismo no marxista y el vitalismo crítico de la ciencia. Como ya se ha comentado, Foster (2000) considera que es necesario que la teoría verde ecosocialista se fundamente en el materialismo ecológico de Marx. ¿Cuál es este materialismo ecológico? Foster comienza por el materialismo de procedencia epicúrea (p. 23). A pesar de que la tesis de graduación de Marx comprenda uno de sus primeros trabajos, esto no debería quitarle el mérito a su escrito. Especialmente porque gracias a Epicuro, se tiene una crítica a la divinidad, cuya ruptura ha sido muy importante para los estudios ecológicos. Contra la Cadena del Ser, que suponía una subyugación del mundo con respecto de los seres humanos y estos a su vez, del dios cristiano, Epicuro y Lucrecio seguían siendo referentes directos.

Sin embargo, Foster comete una pequeña equivocación. Da a entender que Marx conoció a Epicuro por Hegel y Kant, sin incluir el conocimiento de otro filósofo que además fue atomista y materialista: Pierre Gassendi (1592-1655). En su tesis doctoral, Marx comenta "Ya Gassendi elogia a Epicuro (...)" (p. 83). Esto quiere decir, que Marx conocía la obra de Gassendi Vie et Moeurs d'Épicure, donde se hace una descripción detallada de la filosofía epicureista y se refutan a sus adversarios.

En Epicuro existía un rechazo del materialismo determinista, que se traduce en Marx como un rechazo al mecanicismo. Ambos pensadores coincidían en el que universo no está gobernado por leyes deterministas exactas y existe la indeterminación. Esto no lo ideó Marx por sí solo:

Por esto Lucrecio afirma con justicia que la declinación rompe con las fati foedera, y, como él aplica esto enseguida a la conciencia, puede decirse entonces del átomo que la declinación es ese algo en su pecho que puede luchar y resistir (Marx, 1841/2013, p. 70).

Odih (2014) plantea el hecho de que Marx indica como la composición de las necesidades naturales y los movimientos dialécticos que se observan en esto, cambian según se satisfagan de una u otra manera (p. Ixv). De aquí que la fractura metabólica que se desarrolla en el capitalismo esté llevando a la destrucción ambiental. En ese sentido, el materialismo de Salleh determinaría hacia el interior, la manera en la que se comportan las sociedades y los hombres y mujeres que lo componen, explicando la dominación patriarcal desde el ámbito privado y las intenciones desde una "perdida" del yo masculino. El problema es que no considera la propia fractura de las mujeres en su propio materialismo cuando se enfrentan al capitalismo como sociedad en la que viven y trabajan, no considera que sucede hacia el "exterior" social de las mujeres.

Siguiendo con el "materialismo ecológico" que Foster propone, la mirada se pone esta vez en los Manuscritos económico-filosóficos. De esta obra tenemos muchos pasajes citados ampliamente en cualquier obra sobre ecología y Marx. Uno en especial es importante de retomar:

Físicamente, el hombre sólo vive de estos productos naturales, ya se presenten bajo la forma de alimento o la de vestido, calefacción, vivienda, etc. La universalidad del hombre se revela de un modo práctico precisamente en la universalidad que hace de toda la naturaleza su cuerpo inorgánico, en cuanto es tanto 1) un medio directo de vida como 2) la materia, el objeto y el instrumento de su actividad vital (1844/1968, p. 80). 
En este pasaje se hace alusión a diferentes cosas que resultan igual de interesantes. Primero, al hecho de que se establezca la dependencia directa de la humanidad con la naturaleza. Aunque no parezca demasiado, se tiene que recordar toda la tradición teológica que había separado a los seres humanos y sus escalas hasta el dios cristiano. La idea de que la humanidad dependiera de la naturaleza no se defendía de manera material, excepto en el atomismo de Epicuro y Lucrecio. Segundo, la naturaleza (contrariamente a lo que se ha criticado) no es un mero instrumento al servicio de los hombres y mujeres. "Que el hombre vive de la naturaleza quiere decir que la naturaleza es su cuerpo, con el que debe mantenerse en un proceso constante, para no morir" ( $p$. ibíd.) Tercera cosa del pasaje: la importancia de esta interacción práctica.

Foster (2000) también comenta la cita anterior: "Los seres humanos, siguiendo esta concepción, producen en gran medida su propia relación histórica con la naturaleza al producir sus medios de subsistencia" (p. 121). Para el pensador estadounidense esta inferencia es crucial para explicar la concepción materialista de Marx en la naturaleza y en la historia. Esto anterior porque, al igual que Odih, está convencido que Marx continuó con este pensamiento materialista de la naturaleza aun cuando posteriormente se dedicara a la crítica de la economía política. Esto anterior quiere decir que ambos están intrínsecamente conectados. La alienación que aparece en los Manuscritos sería entonces doble: alienación con respecto al trabajo y alienación "con respecto a su papel activo en el proceso de transformación de la naturaleza” (Foster, 2000, p. 121).

Marx aún considera importante referirse a esto en su obra de madurez, El Capital:

Como creador de valores de uso, como trabajo útil, pues, el trabajo es, independientemente de todas las formaciones sociales, condición de la existencia humana, necesidad natural y eterna de mediar el metabolismo que se da entre el hombre y la naturaleza, $y$, por consiguiente, de mediar la vida humana. (1856/2010, p. 53)

La frase parece casi la misma, excepto que ya ha sido atravesada por la teoría del valor y el trabajo. La interacción descrita en los Manuscritos, se ha transformado en "el proceso material de producción de su vida” (p. 97). En medio de esto están, por supuesto, las críticas hacia el materialismo contemplativo de Feuerbach, que es, según Foster (2000), unos de los pasos más significativos de Marx hacia la concepción materialista de la historia (p. 178).

La alienación doble a la que se refiere Foster resulta muy útil para comprender la importancia de un materialismo ecológico fundamentado en Marx. El paso que da Marx hacia la concepción materialista de la historia, lleva consigo la crítica al proceso capitalista de producción, que además condiciona la vida. Aun percibiendo la realidad natural como material, el punto se encuentra fuertemente centrado en la crítica:

La naturaleza no produce por una parte poseedores de dinero o de mercancías y por otra personas que simplemente poseen sus propias fuerzas de trabajo. Esta relación en modo alguno pertenece al ámbito de la historia natural, ni tampoco es una relación social común a todos los períodos históricos. Es en sí misma, ostensiblemente, el resultado de un desarrollo histórico precedente, el producto de numerosos trastrocamientos económicos, de la decadencia experimentada por toda una serie de formaciones más antiguas de la producción social. (El Capital, p. 206) 
En el análisis de Foster (2000), esto tiene una explicación similar. Después de su tesis doctoral y los Manuscritos, el materialismo se fue transformando para beneficio de la crítica:

En ningún momento se ignora en el análisis de Marx el reino de la naturaleza exterior. Sin embargo, al desarrollar el materialismo histórico, tendía a tratar de la naturaleza únicamente en la medida en que entraba dentro de la historia humana, ya que cada vez resultaba más difícil encontrar naturaleza no tocada por la historia humana (p. 181).

De aquí que su transformación sobre el trabajo, incluye la interacción metabólica, tal y como aparece en El Capital (1856/2010 p. 215). Por ello, Foster sentencia: “Fue en El Capital donde la concepción materialista marxiana de la naturaleza se integró plenamente en su concepción materialista de la historia" (p. 220).

Ahora bien, la postura de Salleh con respecto a los fundamentos del materialismo encarnado es ambigua. Esto quiere decir, que partes que son materiales históricas del proceso no pueden ser negadas. Desde el inicio de su libro se comenta y se pone en relación. Aparece claro que, en el proceso de socialización, las mujeres se convierten en sostén del planeta y podría estar configurado de otra forma. No tiene que ver con una idealización del proceso, no son todas las mujeres "guardianas de la biodiversidad" por naturaleza, se encuentran en una resistencia. Vandana Shiva lo explica desde el prólogo de la obra: “No es ningún esencialismo femenino, es una necesidad que surge de la división sexual del trabajo, las mujeres buscan comida, salud, agua, se encargan de los cuidados. Se les enseña esto desde hace miles de años" (Salleh, 2017, p. 14). La producción se asignó a los hombres, la reproducción a las mujeres. Después, esta postura claramente materialista-histórica, se pierde entre la abstracción del proceso que define porqué sucede esto.

Otro de los problemas de que el materialismo encarnado no esté basado en Marx, es que no se establece un límite entre lo que acepta como crítica a la economía política y no, conforme algunas cosas le interesan para sus argumentos. ¿De qué otra manera podría fundamentar la destrucción ambiental? Salleh (2017) no tiene que estar de acuerdo con todas las posturas de Marx. Su teoría está al alcance de las críticas, como todas las demás. Pero es necesario estar de acuerdo con una: las condiciones socio-económicas dentro del capitalismo no son naturales, son históricas. Si las mujeres y sus labores aparecen más cercanas a la naturaleza en el pensamiento del alemán, (y esto es un problema dependiendo, ya que al mismo tiempo es vital en su análisis), en Salleh tienen una exclusión aún mayor de los procesos industriales y no industriales del capitalismo. ¿Ayuda efectivamente esta distancia al análisis ecofeminista marxista? La respuesta es no. Se hace lo mismo que se le critica a Marx.

A pesar de tener una herencia clara del materialismo feminista no marxista, este materialismo encarnado no pretende una crítica al rol de las mujeres más vulnerables, formen estas con su trabajo un modo de producción diferente o no. Si lo menciona, aparece de manera ambigua. Esto refleja parte de los problemas ya señalados. Excluir el materialismo que se funda en Marx, termina por abstraer a este materialismo encarnado de la realidad histórica que viven las mujeres y no funciona para una teoría ecofeminista crítica y anticapitalista como ha sido su supuesta intención. 
La autora afirma: "No hay duda de que la exclusión histórica de las mujeres como "cercanas a la naturaleza” se mantiene como la contradicción social fundante del capitalismo patriarcal” (p. 30). Esto es cierto, pero por el hecho de que el capital necesita aprovecharse de esto para continuar existiendo, es decir, porque esto se traduce en la práctica, en la miseria y el aprovechamiento del trabajo de las mujeres. No porque sus actividades, efectivamente se encuentren en otra esfera aparte "meta-industrial”.

Parece que Salleh está bastante consciente de esto: "La economía convencional está llena del plusvalor apropiado del trabajo femenino sin paga y con poca paga en la interface humanidad/ naturaleza" (p. 30). No se comprende la necesidad de Salleh de rodear la teoría marxiana de la manera en la que lo hace. Excepto que no se fundamente en el materialismo histórico, pero en realidad lo necesite para su propia “criticidad". La "economía convencional" es una forma evasiva de referirse al sistema de producción capitalista y su economía política burguesa. Salleh sabe esto, ella se refiere a cómo el capital tiene una "deuda encarnada" con quienes cumplen las labores de regeneración del planeta. Pero esto no es una "deuda encarnada", porque el capital no tiene cuerpo, es una deuda material e histórica, que se traduce en el materialismo encarnado, en la enseñanza y apropiación del trabajo y el cuerpo de las mujeres.

\section{Conclusiones}

Salleh ha llegado a ampliar la teoría feminista marxista con su materialismo encarnado, ya que este fundamenta la forma en la que la vida de hombres y mujeres se articula de manera diferente desde la infancia. La diferencia por género, un principio establecido dentro del feminismo y el ecofeminismo, puede llegar a tener una fundamentación materialista-marxista en la teoría y la práctica. El materialismo encarnado no es una ley rígida, y debe volver al materialismo ecológico e histórico de Marx para tener algo de inclinación: en este caso es el hecho de no es un destino, son las mujeres más pobres las que deben experimentarlo en gran medida y sostenerlo.

En el texto de Salleh aparecen continuas referencias a las formas en las que se moldeó el proceso que permite el materialismo encarnado. La sola mención de las actividades de trabajo femeninas que lo mantienen, tiene que dar alguna idea de donde procede el análisis de ese proceso. La sociología y el psicoanálisis que utiliza no son suficientes, ya que sólo se enfoca en ciertas partes de los discursos. A pesar de las diferencias que tiene Salleh con Marx, acepta de forma asolapada parte de la concepción materialista de la historia, aunque tenga críticas hacia ella. Partir de una teoría crítica cercana puede ayudar, pero su negación de una postura que, aun criticando la lógica de dominación, pudiese aceptar parte de la fundamentación del materialismo encarnado en el doble materialismo de Marx, no permite superar el esencialismo que se le atribuye.

Se difiere de la separación de esferas para el materialismo encarnado que hace Salleh en lo público y lo privado. Así sea algo que la autora ya ha ido modificando con el paso del tiempo en otros escritos. Sin embargo, el materialismo de esta ecofeminista le puede enseñar algo a la teoría feminista-marxista: ya es hora de dejar de defender el lugar del trabajo femenino entre la "producción" o "reproducción" en el capitalismo, esto es un dualismo patriarcal que se ha establecido bajo términos de dominación. Un ecofeminismo marxista permite la aceptación del verdadero papel que tiene el trabajo femenino en el capitalismo y la tierra en general. El materialismo encarnado puede llenarse de una crítica anticapitalista profunda con la inclusión de la todavía vigente crítica a la economía política. 
La respuesta de las feministas marxistas se ha encargado de explicar cómo el trabajo doméstico sí produce: produce hijos, produce materialidad, etc. Visto desde el materialismo encarnado, no tendría que existir una justificación para defender "la producción" masculina. El rol de las mujeres en la regeneración de la vida en la tierra las pone en el capital constante y el variable y cualquier otro que exista. Se está discutiendo la posibilidad de un cambio importante, dentro de un ecofeminismo marxista, en la forma en que se observa la composición orgánica del capital en sus diferentes etapas y la relación con la naturaleza. También la posibilidad de fundamentar el materialismo encarnado desde una verdadera crítica anticapitalista que implique el desvelamiento de las relaciones económico-políticas que promueven, provocan y se aprovechan de estos procesos para la destrucción de la vida.

\section{Referencias}

Federici, S. (2018). El patriarcado del salario: críticas feministas al marxismo, (traducción María Aránzazu Catalán Altuna). Traficante de Sueños.

Foladori, G. (1990). Metodología materialista para el análisis social. Cuadernos de Extensión.

Foster, J. (2000). La ecología de Marx. El Viejo Topo.

Foster, J. B., \& Burkett, P. (2016). Marx and the Earth. Brill.

Hennessy, R., \& Ingraham, C. (1997). Materialist Feminism: A Reader in Class, Difference, and Women's Lives. Routledge.

Marx, K. (1841/2013). La diferencia entre la filosofía de la naturaleza de Demócrito y Epicuro. Gorla.

Marx, K. (1844/1968). Manuscritos económico-filosóficos de 1844. Grijalbo.

Marx, K. (1856/2010). El Capital tomo I. Siglo XXI.

Mies, M., \& Shiva, V. (1998). La praxis del ecofeminismo. Biotecnología, consumo, reproducción. Icaria y Antrazyt.

Odih, P. (2014). Watersheds in Marxist Ecofeminism. Cambridge Scholars.

Patel, R., \& Moore, J. (2018). A History of the World in Seven Cheap Things: A Guide to Capitalism, Nature, and the Future of the Planet. Black Inc.

Salleh, A. (2006). Moving to an embodied Materialism. Capitalism Nature Socialism 16(2), 9-14. http:// doi.org/10.1080/10455750500108195

Salleh, A. (2009). Nature, woman, labor, capital: living the deepest contradiction. Capitalism Nature Socialism 6(1), 21-39. hhtp://doi.org/10.1080/10455759509358619

Salleh, A. (2017). Ecofeminism as Politics; Nature, Marx and the Postmodern. Zed Books.

Tardón, V. (2011). Ecofeminismo. Una reivindicación de la mujer y la naturaleza. El futuro del pasado: revista electrónica de historia, 2, 533-542.

Wolfe, C. T. (2012). Forms of Materialist Embodiment. En, M. Landers y B. Muñoz (Ed.), Anatomy and the organization of Knowledge 1500-1850, (pp. 129-144). Pickering y Chatto. 


\section{AUTORA}

Karol Badilla-Fallas. Estudiante de Licenciatura en Filosofía de la Universidad de Costa Rica, Bachiller en Filosofía por la misma universidad.

Conflicto de intereses

La autora Karol Badilla-Fallas declara que no existe conflicto de interés posible.

Financiamiento

No existió asistencia financiera de partes externas al presente artículo.

Agradecimientos

Agradezco al Dr. George García por sus observaciones en el artículo y sus enseñanzas.

Nota

El artículo procede de la conferencia “La recepción de Marx desde el ecofeminismo" presentada en las Jornadas de Investigación Filosóficas de la Universidad de Costa Rica en octubre de 2020. 